\title{
A social-ecological perspective on health in urban environments
}

\section{Allen Kearns ${ }^{\mathrm{A}, \mathrm{B}}$, Matthew Beaty ${ }^{\mathrm{A}}$ and Guy Barnett ${ }^{\mathrm{A}}$}

A Urban Systems Program, CSIRO Sustainable Ecosystems.

BCorresponding author: Allen.Kearns@csiro.au

\begin{abstract}
Human health in our cities is an expression of complex social and environmental interactions not previously faced in our long evolutionary history. In this paper, we present a social-ecological perspective on the complex nature of emerging public health problems in cities and identify some of the research questions emerging from this new view of the city. We argue that an integrative urban science agenda is needed not only to inform urban policy, planning and design, but also to alert people to the consequences of and trade-offs around their choices and behaviours.
\end{abstract}

Our cities are dynamic places where increasing numbers of people are choosing to live their lives. The present built form of the city closely reflects: (i) the geography and ecological history of particular places; (ii) the historic interactions between founding populations of people; (iii) how they used the natural resources they found; and (iv) how they decided to build infrastructure in their new environment. ${ }^{1-3}$ In any city you can see how urban settlement patterns have been shaped by cumulative decisions that at first influence and then determine the trajectories of urban, industrial and infrastructure developments. Global drivers of change, such as climate variability, globalising markets, terrorism, rapid urbanisation, increasing human populations, rising per capita consumption and risk of pandemic disease also influence the development of cities. ${ }^{4,5}$ These factors represent some of the main challenges for the future health of people in cities and their urban bioregions, the ecological systems on which cities depend. ${ }^{6}$

\section{Urban environments and health}

Urban environments are rapidly changing, and people as individuals and as part of organisations are constantly adapting to new opportunities and threats. Not surprisingly, along with the benefits that urban life brings to many, there are a range of old and new health risks that are now affecting increasing numbers of individuals and their communities. In the 20 th century, public health, civil engineering and environmental science were successful in reducing the incidence of health problems through point source treatment of clean water, the removal and treatment of wastewater and garbage, and the regulation of industrial wastes, effluents and emissions. ${ }^{7,8}$ The rising tide of $21 \mathrm{st}$ century public health problems, such as obesity, cardiovascular disease and depression, are different to past problems that could be directly attributed to infectious agents, toxic chemicals, poor industrial design and a lack of effective environmental management.

The new diseases of urban living arise more from the complex way we now live, eat, travel, build, play and work in urban environments, rather than from any single agency. Our health is now an expression of a complex web of interactions that have not been previously faced during human evolution and these interactions are more subtle and indirect in their action. They include factors such as: (i) the time we spend commuting to work; (ii) how we individually respond to the abundance of energy-rich foods and drinks brought to us through the industrial food chain; (iii) the availability or otherwise of opportunities to be physically active; and (iv) the time we have for self-reflection and family. While these factors act on individuals, all have become highly socially organised and mediated through changing cultural aspirations and norms, urban systems of governance, infrastructure, modes of transport, and the supply and demand of urban goods and services such as food, water, energy and transport.

\section{Cities as social-ecological systems}

A social-ecological perspective focuses on cities as 'urban ecosystems', as distinct from the traditional 'ecology in the city' approach, which addresses the distribution, abundance and management requirements of biodiversity in the city. ${ }^{9}$ The urban ecosystem approach views the city as a distinct type of ecosystem characterised by the linkages between social and ecological processes and asks questions about the spatial, systems and social context of urban people and the extent of their interdependence on their urban bioregion. For example, from where do urban people derive their water, energy and food; where do people spend most of their time; how far do they travel to work, school and recreational outlets; and what social-ecological conditions contribute to their cultural identity, sense of place and health? The urban ecosystem approach also identifies our interdependence on natural 
systems in remote catchments and urban environments to provide biodiversity and ecosystem services (i.e. those unpriced ecological processes provided by natural systems that clean our water and air, pollinate our plants, recycle our nutrients and enhance our urban quality of life and our health through the rejuvenating aspects of recreation). The urban ecosystem approach is a human-based ecology that recognises the critical aspects of urban systems of governance in sustaining urban quality of life. In particular, urban people have a strong social and institutional dependence on reliable flows of goods and services such as water, energy, food, construction materials, transport, health services, information and capital to sustain health.

As an example, the Extended Urban Metabolism Model ${ }^{10}$ (Fig. 1) provides a useful social-ecological framework for linking the industrial production of these urban resource inputs (food, materials, water, energy and information) to the spatial patterns and organisational processes that characterise urban consumption. Resources, both physical and social, are transformed, or 'metabolised', and distributed through urban governance systems and infrastructure networks with emergent consequences for people and urban environments. Research can be directed at developing a better understanding of the effect of these processes on the health of people in cities. For example, what factors increase the rates of industrial production of high-energy, low-cost foods and what are the consequences for targeted populations of urban consumers? Or, what are the social and health costs of inadequate transport infrastructure and consequent loss of personal and family time from long commutes to work and sedentary lifestyles?

\section{Research questions generated from a social-ecological perspective}

A social-ecological perspective could enable research into:

- The spatial and temporal dynamics of social and environmental determinants of human health in urban systems. ${ }^{11}$ Who gets sick and where do they live?

What are the relative contributions of social versus environmental factors? What types of interventions are available and appropriate?

- Measures of health in different urban forms. ${ }^{12,13}$ What contribution does urban pattern and social-ecological processes in urban environments make to the functionality of urban habitats? Can we identify the characteristics of dysfunctional and functional urban landscapes and incorporate this knowledge into better urban planning, design, construction and management?

- Urban resilience to shocks and disturbances caused by natural and human disasters. ${ }^{14,15}$ Can we identify aspects of our social, natural and built environment that make us vulnerable? Can we build resilience into our infrastructure and the way we organise ourselves as communities?

\section{- Maintenance of ecosystem services and food} production in urban environments. ${ }^{16}$ In both cities and the rapidly urbanising rural lands that surround them, how important is it to conserve natural systems and sustain agricultural lands for healthy local food production? What role could this play in preserving our long-term environmental and food security?

- Social capital for coping with and adapting to change in urbanising landscapes. ${ }^{17}$ How prepared are existing rural and urban communities to adapt to the pace and scale of changes caused by rapid urbanisation? What are the health consequences of the inability of local people to adapt to changing urban transport patterns, social processes and globalisation?

- Measures of urban quality of life that address the effects of surplus consumption. ${ }^{18}$ What educational changes, and access to information and knowledge, are necessary to raise awareness about the individual health consequences of surplus consumption, particularly of food, but also of energy, water and construction materials? What policy platforms are needed to create an enabling environment for better urban health?

This social-ecological perspective ${ }^{19}$ on the complex nature of emerging public health problems presents a

\begin{tabular}{|c|c|c|}
\hline $\begin{array}{l}\text { Urban resource } \\
\text { inputs }\end{array}$ & $\begin{array}{l}\text { Urban systems and } \\
\text { processes }\end{array}$ & Outcomes \\
\hline \multirow[t]{3}{*}{$\begin{array}{l}\text { People, Information, Food } \\
\text { Energy, Water, Materials, } \\
\text { Transport, Housing, } \\
\text { Land, Biodiversity }\end{array}$} & \multirow{3}{*}{$\begin{array}{l}\text { Urban governance } \\
\text { Industrial processes } \\
\text { Distribution of goods } \\
\text { Provision of services } \\
\text { Urban design and } \\
\text { development }\end{array}$} & $\begin{array}{l}\text { Liveability } \\
\text { Health } \\
\text { Environmental health } \\
\text { Culture and heritage }\end{array}$ \\
\hline & & $\begin{array}{l}\text { Urban environmental } \\
\text { quality } \\
\text { Air, Water, Noise }\end{array}$ \\
\hline & & Wastes and emissions \\
\hline
\end{tabular}

Fig. 1. The Extended Urban Metabolism Model adapted from Newton et al. ${ }^{10}$

This simplified version of the model provides a useful checklist of inputs, processes and outcomes that need to be considered in a social-ecological framework. 
major new challenge for how urban society generates the understanding required to find an integrated set of solutions that address these complex problems. Partial solutions generated by traditionally distinct professional disciplines are unlikely to match the spatial scale and pace of these emerging health problems in urban environments. However, more integrated solutions will require health professionals, epidemiologists, engineers, environmental scientists, urban planners, designers and managers, policy specialists, economists and social scientists to come to grips with working together in new ways. ${ }^{20}$ For example, an integrated approach to urban science would require interdisciplinary knowledge from many areas to address the complex social-ecological interactions that are contributing to the rise of overweight and obese people in increasingly dysfunctional urban environments. Researchers working in partnership with people in urban practice, policy and communities will be an essential part of a research agenda for sustainable development that would address these complex health problems. Changes will also be needed in how we plan, design, construct, monitor and evaluate old and new urban developments to identify what interventions enhance the prospects for people to improve their health as part of their day-to-day interactions in rapidly urbanising landscapes.

\section{Conclusion}

To have any affect on the health of people in urban environments, urban society will require the integration of new urban science knowledge into urban planning and the design and construction of healthier homes, workplaces, community centres, recreation areas, mobility and transport infrastructure. Our built form, the basic template in which we live out the majority of our lives and social interactions, must be planned, designed and constructed to encourage, not hinder, healthy behavioural changes in food availability, mobility options, workplace practices and lifestyle choices. In a broader sense, an urban science agenda is needed not only to inform urban policy, planning and design but to also educate people about the consequences of and trade-offs around the choices they make. In the end, cities, as engines of creativity and innovation, may also be our best hope for providing solutions to many of these pressing problems and long-term sustainability issues. ${ }^{21}$

For more information:

CSIRO Sustainable Ecosystems

http://www.csiro.au/org/cse.html

ECOS Magazine http://www.publish.csiro.au/?nid = 214

\section{References}

1. Grimm NB, Grove JM, Pickett STA, Redman CL. Integrated approaches to long term studies of urban ecological systems. Bioscience 2000; 50(7): 571-84. doi:10.1641/00063568(2000)050[0571:IATLTO]2.0.CO;2

2. Cronon W. Nature's metropolis: Chicago and the great west. New York: W. W. Norton and Company, 1991.
3. Thayer RJ Jr. LifePlace: bioregional thought and practice. Berkeley: University of California Press, 2003.

4. Tainter J. The collapse of complex societies. Cambridge: Cambridge University Press, 1990.

5. Diamond J. Collapse: how societies choose to fail or succeed. New York: Viking Penguin, 2005.

6. Millennium Ecosystem Assessment. Ecosystems and human well-being: synthesis. Washington DC: Island Press, 2005.

7. Porter D. Health, civilization, and the state: a history of public health from ancient to modern times. New York: Routledge, 1999.

8. McMichael AJ. Human frontiers, environments, and disease. Cambridge: Cambridge University Press, 2001.

9. Pickett STA, Birch WL Jr, Dalton SE, Foresman TW. Integrated urban ecosystem research. Urban Ecosyst 1997; 1: 183-4. doi:10.1023/A:1018579628818

10. Newton PW, Baum S, Bhatia K, Brown SK, Cameron AS, Foran B, et al. Human settlements, Australia State of the Environment Report 2001 (Theme Report). Melbourne: CSIRO Publishing on behalf of the Department of the Environment and Heritage, Canberra, 2001.

11. Butler CD, Corvalan CF, Koren HS. Human health, well-being, and global ecological scenarios. Ecosystems 2005; 8: 153-62. doi:10.1007/s10021-004-0076-0

12. Jackson LE. The relationship of urban design to human health and condition. Landsc Urban Plan 2003; 64: 191-200. doi:10.1016/S0169-2046(02)00230-X

13. Jackson LE, Hilborn ED, Thomas JC. Towards landscape design guidelines for reducing Lyme disease risk. Int $J$ Epidemiol 2006; 35: 315-22. doi:10.1093/ije/dyi284

14. Allenby B, Fink J. Towards inherently secure and resilient societies. Science 2005; 309: 1034-6.

15. Vale LJ, Campanella TJ, editors. The resilient city: how modern cities recover from disaster. Oxford: Oxford University Press, 2005.

16. Viljoen A, editor. Continuous productive urban landscapes: designing urban agriculture for sustainable cities. Oxford: Architectural Press, 2005.

17. Walker B, Holling CS, Carpenter SR, Kinzig A. Resilience, adaptability and transformability in social-ecological systems. Ecol Soc 2004; 9(2): 5. [online] URL: http://www.ecologyandsociety.org/vol9/iss2/art5 [Verified 23 April 2007].

18. Hamilton C, Denniss R. Affluenza: when too much is never enough. Sydney: Allen and Unwin, 2005.

19. Berkes F, Colding J, Folke C, editors. Navigating socialecological systems: building resilience for complexity and change. Cambridge: Cambridge University Press, 2003.

20. Pickett STA, Birch WL Jr, Grove JM. Interdisciplinary research: maintaining the constructive impulse in a culture of criticism. Ecosystems 1999; 2: 302-7. doi:10.1007/ s100219900081

21. Pearce F. Ecopolis now: forget the rural idyll - urban living may be the best way to save the planet. New Scientist 2006; 2556: $36-42$. 